\title{
THE EFFECTS OF NITRITE ON BEHAVIOR AND METAMORPHOSIS IN CASCADES FROGS (RANA CASCADAE)
}

\author{
Adolfo Marco*† and Andrew R. Blaustein $\$$ \\ $\dagger$ Departamento de Biologia Animal, Universidad de Salamanca, Salamanca 37071, Spain \\ $\ddagger$ Department of Zoology, Oregon State University, Corvallis, Oregon 97331, USA
}

(Received 26 May 1998; Accepted 27 July 1998)

\begin{abstract}
Amphibian metamorphosis is a period of drastic morphologic reorganization, during which larvae experience a decrease in locomotor ability and are more vulnerable to predation. Our results indicate that exposure to sublethal concentrations of nitrite in the water induces behavioral and morphologic changes in the Cascades frog (Rana cascadae). Tadpoles exposed to a nitrite concentration of $\mathrm{N}^{-\mathrm{NO}_{2}^{-}}$at $3.5 \mathrm{mg} / \mathrm{L}$ transformed more slowly than control tadpoles exposed to dechlorinated tap water. No difference was found in time at emergence and snout-vent length at emergence between experimental and control tadpoles, but development was retarded in tadpoles exposed to nitrite and they emerged at an earlier developmental stage. Also, tadpoles exposed to nitrite occupied shallow water more frequently than did control tadpoles.
\end{abstract}

Keywords-Amphibian Fertilizers Metamorphosis Nitrite Rana cascadae

\section{INTRODUCTION}

Numerous anthropogenic agents such as acid precipitation, increased UV-B radiation, chemical pollutants, and introduced exotic species have contributed to population declines or local extinctions of various animal species [1-3] and may be affecting many amphibian populations [4-9]. Although the effects of some of the agents affecting amphibians have been studied in more detail than others, very little information is available on the effects of fertilizers on amphibians. Nitrogenbased fertilizers may significantly affect amphibians at numerous locales because these fertilizers are widely applied at relatively large concentrations in areas heavily populated by humans, and these fertilizers are also used in remote forests in sparsely populated areas $[10,11]$.

Inorganic pollutants in the water are toxic to larval and adult stages of many amphibian species [12-16]. For example, increased concentrations of nitrogenous compounds in surface water from various sources from agricultural land are hazardous to many species of wildlife [17-19]. Under some conditions, nitrates and ammonia can be transformed to nitrites in the field or in the digestive systems of animals as a result of bacterial metabolism [20]. When nitrites contact blood plasma, they transform hemoglobin to methemoglobin, decreasing the oxygen carrying capacity of the blood [20]. Evidence is suggestive of the negative effects of nitrite (methemoglobinemia) in humans and fishes [21-23]. Moreover, recent experiments have shown that low levels of nitrite have a negative effect on the aquatic larval stages of some amphibians [24-28]. The early stages of many amphibians are restricted to the aquatic environment, and are susceptible to dermal absorption of toxic compounds and to ingestion of contaminated materials in the water [12,29].

Amphibian metamorphosis is a period of extensive morphologic reorganization and we hypothesize that exposure to

* To whom correspondence may be addressed (marcoa@gugu.usal.es). nitrite may affect this process. Therefore, we tested the effect of nitrite on metamorphosis of the Cascades frog (Rana cascadae) in the laboratory. Cascades frogs are susceptible to a number of environmental stresses including pathogens and UV-B radiation [4,5] and their populations are in decline throughout their range $[9,30]$.

\section{MATERIALS AND METHODS}

\section{Tadpole collection and culture}

Premetamorphic Cascades frog tadpoles were collected close to their maximum body size and before arm eruption (Gosner stages 38-40) [31] from a pond in Deschutes County, Cascades Mountains of Oregon, USA, during the first week of August 1997. Tadpoles were collected in areas where they were abundant. Tadpoles were transported to the laboratory and were housed in 30-L glass containers at approximately $20^{\circ} \mathrm{C}$ under artificial incandescent light with a natural photoperiod. Tadpoles were fed lettuce ad libitum that was previously washed with distilled water and boiled for $1 \mathrm{~min}$. No tadpoles died or had visible abnormalities in the containers. The experiment began $10 \mathrm{~d}$ after tadpoles were collected.

\section{Experimental procedures}

The effects of nitrite on Cascades frog tadpoles undergoing metamorphosis were tested in static tests [32]. The experiment was conducted in August (1997) in the laboratory at approximately $20^{\circ} \mathrm{C}$ under artificial light with a natural photoperiod. Tests were conducted in plastic tanks $(80 \times 40 \times 14 \mathrm{~cm})$ containing $9 \mathrm{~L}$ of dechlorinated tap water. The tanks were tilted at an angle (approximately $20^{\circ}$ ) so that half of the floor of each tank was submerged and the other half was completely dry. One hundred $R$. cascadae tadpoles (stage 39-40, before forelimb eruption [31]) were randomly selected and 10 were placed on the side with water of each tank. The 10 tanks were randomly assigned to either control ( 5 tanks) or nitrite ( 5 tanks) treatments. Sodium nitrite was used in the solutions. Thirty 
Table 1. Results of multivariate analyses of variance that analyze the overall effect of nitrite on Rana cascadae metamorphosis

\begin{tabular}{|c|c|c|c|c|}
\hline Effect & Variable & $d f$ & $F$ & $p$ \\
\hline Snout-vent length (covariate) & All & 4,4 & 13.179 & 0.014 \\
\hline Nitrite & All & 4,4 & 10.681 & 0.021 \\
\hline Nitrite & Time to emergence & 1,7 & 1.612 & 0.245 \\
\hline Nitrite & Time to stage 42 & 1,7 & 5.826 & 0.047 \\
\hline Nitrite & Tail loss rate & 1,7 & 6.876 & 0.034 \\
\hline Nitrite & Head out of water & 1,7 & 37.700 & $<0.001$ \\
\hline
\end{tabular}

milliliters of nitrite solution was added to the water in each tank for a final concentration of $\mathrm{N}^{-\mathrm{NO}_{2}^{-}}$of $3.5 \mathrm{mg} / \mathrm{L}$. Thirty milliliters of dechlorinated water was added to the control tanks. The sublethal nitrite concentration was based on pilot trials conducted for other amphibian species (Rana pretiosa and Rana aurora). Dechlorinated tap water that was chemically treated to remove ammonia, chlorine, chloramine and heavy metals, and to buffer $\mathrm{pH}$, was used. Tadpoles were fed lettuce ad libitum that was washed with distilled water and boiled for $1 \mathrm{~min}$. Solutions were replaced and tanks were cleaned at days 5 and 10. The experiment was conducted for $14 \mathrm{~d}$. The experiment ended when at least six tadpoles from every tank emerged from the water. Tadpoles were considered to have emerged from the water if they were found in the upper one-third of the dry half of the tank, or if they had climbed to the top of the tank, above the level of the water. Tadpoles that emerged from the water were removed from the tank.

To determine whether tadpoles had a behavioral response to nitrite we recorded in each tank, over a 30-s span every 12 $\mathrm{h}$, the number of tadpoles with their heads out of the water. To detect an effect of nitrite on metamorphosis we recorded in each tank and every $12 \mathrm{~h}$, the number of tadpoles with erupted forelimbs (Gosner stage 42). To determine whether nitrite had an effect on emergence from water, we recorded time to emergence, snout-vent length, and tail length of emerging tadpoles. Tail loss rate was also calculated to determine if nitrite had a morphologic effect in metamorphosis. To estimate this rate for each emerging metamorph, we considered as initial value of tail length the average tail length of 20 tadpoles randomly selected and measured the day when the experiment began. These tadpoles were not used in the experiment.

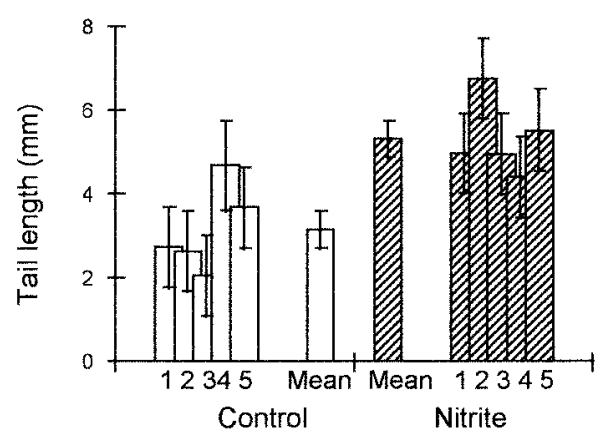

Fig. 1. Tail length (mean $\pm \mathrm{SD}$ ) at metamorphosis of Rana cascadae tadpoles exposed to water with a sublethal concentration of nitrite versus tadpoles in water without nitrite. Numbers 1 through 5 are individual tanks containing 10 tadpoles, receiving the control and experimental (nitrite) treatment. Mean and standard deviation are shown for each tank, with an overall mean \pm standard deviation for control and treatment.

\section{Analysis of data}

Multivariate analysis of covariance (MANCOVA) was used to determine whether nitrite had an overall effect on tadpole metamorphosis, considering as dependent variables, time to emergence, tail loss rate until emergence, time to Gosner stage 42 , and number of tadpoles observed with their heads out of water. The independent variable was the snout-vent length of tadpoles. Post hoc analyses of covariance were used to determine the effects of exposure to nitrite on each variable.

\section{RESULTS}

No tadpoles died. The MANCOVA indicated an overall effect of exposure to nitrite on Cascades frog metamorphosis. No significant effects were found on juvenile snout-vent length at emergence (Student's $t$ test; $t=0.56, p=0.592$ ) and time to emergence (Table 1). Tadpoles started to emerge after an exposure of $96 \mathrm{~h}$. The average time to emergence was $175 \mathrm{~h}$ (range $=96-324 \mathrm{~h})$ for control tadpoles and $184 \mathrm{~h}$ (range $=$ 96-336 h) for tadpoles in water with nitrite. However, tadpoles in water with nitrite had slower development and slower rate of tail loss (Fig. 1) and consequently emerged with longer tails than control tadpoles. Moreover, during metamorphosis we detected behavioral differences among treatments. Tadpoles in water with nitrite were more frequently found in shallow water where their heads were out of water (Table 1 and Fig. 2).

\section{DISCUSSION}

Low concentrations of nitrite may have negative effects on amphibian larval survival $[26,27]$. Among these effects is the oxidation of hemoglobin to methemoglobin. This conversion hampers oxygen transport in blood. Thus, methemoglobinemia can cause tissue hypoxia and eventually death of affected an-

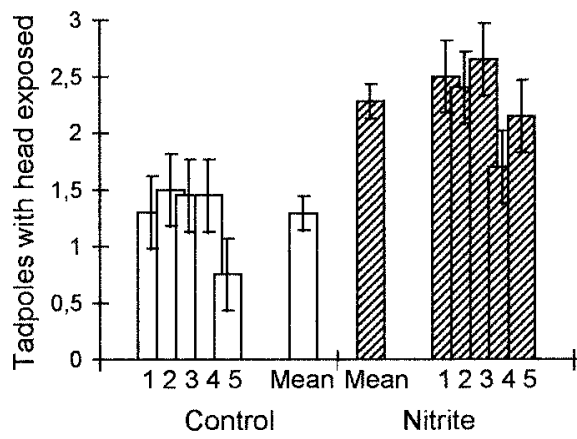

Fig. 2. Behavioral effect (measured as number of tadpoles partially exposing their head out of the water) of sublethal concentrations of nitrite on Rana cascadae tadpoles during metamorphosis. Numbers 1 through 5 are individual tanks containing 10 tadpoles, receiving the control and experimental (nitrite) treatment. Mean and standard deviation are shown for each tank, with an overall mean \pm standard deviation for control and treatment. 
imals [20]. The lethal effects of nitrites are related to ion concentration and have been documented mainly in early stages of development, but some animal species may become more tolerant of nitrite as they grow [33]. Tadpoles at later developmental stages may be more tolerant to nitrite than those in earlier stages. However, nitrites have some sublethal effects on aquatic vertebrates. Nitrites may affect swimming performance, growth, and development and cause morphologic abnormalities [22,34]. The nitrite concentration used in this study is lethal for newly hatched larvae of several amphibians $[26,27]$. This concentration of nitrite was not lethal for Cascades frog tadpoles undergoing metamorphosis. However, some sublethal effects on tadpole development and behavior were detected.

In this study, tadpoles that were exposed to nitrite transformed more slowly than did control tadpoles. Oxygen consumption is relatively high throughout metamorphosis [35] and hypoxia due to exposure to nitrite could have a negative effect in tadpole metabolism. Nitrite may cause tissue hypoxia in tadpoles, thus affecting and slowing the physiologic and morphologic changes that take place during metamorphosis.

If nitrite hampers growth and development and stage to emergence from water in larval amphibians, the larvae may be more prone to predation. Transforming tadpoles of some anuran species have a higher predation rate by snakes than larvae or juveniles [36]. Larvae undergoing metamorphosis would be incompletely suited to their new terrestrial habitat if they had not completely transformed [37]. For example, they would have limited ability to move in the terrestrial environment, and be more vulnerable to predation. In this study, premetamorphic tadpoles exposed to nitrite emerged from water at an early stage of development, conserving characteristics of the larval stage, such as relatively long tails. Thus, the effect of nitrite on stage to emergence from water could potentially increase the rate of predation on these tadpoles.

Methemoglobinemia could also explain the observed behavioral responses of tadpoles to nitrite. In this study, tadpoles in water with nitrite occupied shallow water more often than did controls, perhaps because they were trying to get more oxygen. Bobbing behavior has been described in many amphibians and apparently the bobbing rate is related to oxygen availability in water [38]. At hypoxic conditions, tadpoles may also increase their frequency of breathing [39]. We suggest that tissue hypoxia due to exposure to nitrite could force tadpoles to shift their habitat use to shallow water, so that they can breathe more efficiently. However, given that tadpoles are not suited to terrestrial life, the presence of tadpoles near the shore could increase their risk of predation.

In summary, we have shown that brief exposure to nitrites affects the growth and behavior of $R$. cascadae tadpoles during a critical time period in their development. Because nitrogenous fertilizers are applied to many locales, it is possible that they are adversely affecting amphibians at the larval stage. These effects have not been intensively studied but they may ultimately affect amphibians at the population level.

Acknowledgement-We thank Chelo Quilchano, Erica Wildy, Lisa Belden, Ole Stabell, Audrey Hatch, and David Cash. We also thank $\mathrm{Cal}$ Meachum, Ruth Adams, and Steve Carlson. Funding was provided by the Ministry of Education and Culture of Spain grant E9516796691 to A. Marco; Oregon State University, Department of Zoology Research Funds; and National Science Foundation of USA grant DEB 9423333 to A.R. Blaustein.

\section{REFERENCES}

1. Ehrlich PR, Ehrlich AH, Pimm S. 1996. Betrayal of science and reason. Nature 383:494.

2. Wake DB. 1991. Declining amphibian populations. Science 253: 422-424.

3. Wilson EO. 1992. The Diversity of Life. Belknap, Cambridge, MA, USA.

4. Kiesecker JM, Blaustein AR. 1995. Synergism between UV-B radiation and a pathogen magnifies amphibian embryo mortality in nature. Proc Natl Acad Sci USA 92:11049-11052.

5. Blaustein AR, Hoffman PD, Hokit DG, Kiesecker JM, Walls SC, Hays JB. 1994. UV-repair and resistance to solar UV-B in amphibian eggs: A link to population declines? Proc Natl Acad Sci USA 91:1791-1795.

6. Kiesecker JM, Blaustein AR. 1997. Population differences in responses of red-legged frogs (Rana aurora) to introduced bullfrogs. Ecology 78:1752-1760.

7. Blaustein AR, Wake DB, Sousa WP. 1994. Amphibian declines: Judging stability, persistence, and susceptibility of populations to local and global extinctions. Conserv Biol 8:60-71.

8. Reaser JK. 1996. The elucidation of amphibian declines: Are amphibian populations disappearing? Amphib Reptile Conserv 1:4-9.

9. Stebbins RC, Cohen NW. 1995. A Natural History of Amphibians. Princeton University Press, Princeton, NJ, USA.

10. Gessel SP, Atkinson WA. 1984. Use of fertilizers in sustained productivity of Douglas-fir forests. In Stone EL, ed, Forest Soils and Treatment Impacts. University of Tennessee, Knoxville, TN, USA, pp 125-140.

11. Norse EA. 1990. Ancient Forests of the Pacific Northwest. The Wilderness Society, Washington, DC, USA.

12. Berger L. 1989. Disappearance of amphibian larvae in the agricultural landscape. Ecol Inter Bull 17:65-73.

13. Devillers J, Exbrayat JM. 1992. Ecotoxicity of Chemicals to Amphibians. Handbooks of Ecotoxicological Data, Vol 1. Gordon and Breach Science, Philadelphia, PA, USA.

14. Fulton MH, Chambers JE. 1985. The toxic and teratogenic effects of selected organophosphorus compounds on the embryos of three species of amphibians. Toxicol Lett 26:175-180.

15. Lefcort H, Hancock KA, Maur KM, Rostal DC. 1997. The effects of used motor oil, silt, and the water mold Saprolegnia parasitica on the growth and survival of mole salamanders (genus Ambystoma). Arch Environ Contam Toxicol 32:383-388.

16. Mahaney PA. 1994. Effects of freshwater petroleum contamination on amphibian hatching and metamorphosis. Environ Toxicol Chem 13:259-265.

17. Bogardi I, Kuzelka RD, Ennenga WG. 1991. Nitrate Contamination: Exposure, Consequence, and Control. NATO ASI Series G-Ecological Sciences, Vol 30. Springer-Verlag, New York, NY, USA.

18. Hecnar SJ. 1995. Acute and chronic toxicity of ammonium nitrate fertilizer to amphibians from southern Ontario. Environ Toxicol Chem 14:2131-2137.

19. Russo RC, Thurston RV. 1977. The acute toxicity of nitrite to fishes. In Tubb RA, ed, Recent Advances in Fish Toxicology. U.S. Environmental Protection Agency, Corvallis, OR.

20. Eddy FB, Williams EM. 1994. Freshwater fish and nitrite. In Howells G, ed, Water Quality for Freshwater Fish. Gordon and Breach Science, Yverdon, Switzerland, pp 117-143.

21. Lewis WM Jr, Morris DP. 1986. Toxicity of nitrite to fish: A review. Trans Am Fish Soc 115:183-194.

22. Organization for Economic Cooperation and Development. 1986. Water Pollution by Fertilizers and Pesticides. Paris, France.

23. Williams EM, Eddy FB. 1989. Effect of nitrite on the embryonic development of Atlantic salmon (Salmo salar). Can J Fish Aquat Sci 46:1726-1729.

24. Dappen GE. 1982. Effects of nitrates upon hemopoietic, lymphoid and vascular tissues of tadpoles and frogs. Proc Nebr Acad Sci 92:23.

25. Huey DW, Beitinger TL. 1980. Hematological responses of larval Rana catesbeiana to sublethal nitrite exposures. Bull Environ Contam Toxicol 25:574-577.

26. Huey DW, Beitinger TL. 1980. Toxicity of nitrite to larvae of the salamander Ambystoma texanum. Bull Environ Contam Toxicol 25:909-912.

27. Oldham RS, Hilton-Brown D. 1992. Effect of agricultural fertilizers on amphibians (C): NPK granules tested separately. Report F72-15-05. Nature Conservancy Council, London, UK. 
28. Watt PJ, Oldham RS. 1995. The effect of ammonium nitrate on the feeding and development of larvae of the smooth newt, Triturus vulgaris (L.), and on the behaviour of its food source, Daphnia. Freshwater Biol 33:319-324.

29. Cooke AS. 1981. Tadpoles as indicators of harmful levels of pollution in the field. Environ Pollut Ser A 25:123-133.

30. Fellers GM, Drost CA. 1993. Disappearance of the Cascades frog Rana cascadae at the southern end of its range, California, USA. Biol Conserv 65:177-181.

31. Gosner KL. 1960. A simplified table for staging anuran embryos and larvae with notes on identification. Herpetologica 16:183190.

32. Stephen CE. 1975. Methods for acute toxicity tests with fish, macroinvertebrates and amphibians. EPA-660/3-75-009. U.S. Environmental Protection Agency, Corvallis, OR.

33. U.S. Environmental Protection Agency. 1986. Quality criteria for water. EPA-440/5-86-001. Washington, DC.
34. Oldham RS, Lathan DM, Hilton-Brown D, Towns M, Cooke AS, Burn A. 1997. The effect of ammonium nitrate fertilizer on frog (Rana temporaria) survival. Agric Ecosyst Environ 61:69-74.

35. Feder ME. 1982. Effect of developmental stage and body size on oxygen consumption of anuran larvae: A reappraisal. J Exp Zool 220:33-42.

36. Wassersug RJ, Sperry DG. 1977. The relationship of locomotion to differential predation on Pseudacris triseriata (Anura: Hylidae). Ecology 58:830-839.

37. Huey RB. 1980. Sprint velocity of tadpoles (Bufo boreas) through metamorphosis. Copeia 1980:537-540.

38. Wassersug RJ, Seibert EA. 1975. Behavioral responses of amphibian larvae to variation in dissolved oxygen. Copeia 1975: 86-103.

39. West NH, Burggren WW. 1982. Gill and lung ventilatory responses to steady-state aquatic hypoxia and hyperoxia in the bullfrog tadpole. Respir Physiol 47:165-176. 